\title{
Article
}

\section{Simple Measurement Method with High Detection Efficiency to Evaluate Sr-90 Concentration in Water by Measuring $\beta$ rays from Y-90 Using GM-Detector}

\author{
Kenjiro KONDO ${ }^{1, *}$, Hideo HIRAYAMA ${ }^{1}$, Masafumi TAIRA ${ }^{1}$, \\ Hiroshi MATSUMURA ${ }^{1}$, Hiroshi IWASE ${ }^{1}$ and Shinichi SASAKI ${ }^{1}$ \\ ${ }^{1}$ High Energy Accelerator Research Organization, 1-1 Oho, Tsukuba-shi, Ibaraki 305-0801, Japan
}

\begin{abstract}
Strontium-90/Y-90 are major radionuclides observed in the water samples tested recently at the site of the Fukushima Daiichi Nuclear Power Plant of Tokyo Electric Power Company. A simple method of evaluating Sr-90 concentration in these water samples by measuring $\beta$ rays from Y-90 with a GM-detector setup was developed. By applying the precipitation method, Sr90 and Y-90 were separated and quantitatively collected with a filter. $\beta$ rays from Y-90 in the filter were measured two times at appropriate intervals by inserting a polyethylene plate of $2 \mathrm{~mm}$ thickness as a $\beta$-ray absorber. The contribution of $\gamma$ rays from Cs-134 and Cs- 137 to the Y-90 count rates was quantitatively evaluated using a 10 -mm-thick acrylic resin plate. From the parent-daughter relationship between Sr-90 and Y-90, the Sr-90 concentration was evaluated using the conversion coefficient of $\mathrm{Y}-90$ count rate $(\mathrm{cps})$ to $\mathrm{Sr}-90$ concentration $\left(\mathrm{Bq} / \mathrm{cm}^{3}\right)$. It was verified that $\mathrm{Sr}-90$ concentration of below $0.01 \mathrm{~Bq} / \mathrm{cm}^{3}$ in water samples can be correctly measured by this simple method.
\end{abstract}

KEYWORDS: Sr-90/Y-90, Sr-90 concentration, Y-90 $\beta$ ray, GM-detector, coprecipitation

\section{Introduction}

At the Fukushima Daiichi Nuclear Power Plant of the Tokyo Electric Power Company (hereinafter referred to as " $1 \mathrm{~F}$ power station"), various kinds of radioactive-contaminated water were generated due to the accident. Accurate determination of the radioactive concentration in the contaminated water is one of the most important tasks in the ongoing process towards recovery from the accident.

The major radionuclides contained in the contaminated water from the $1 \mathrm{~F}$ power station are Sr-90 and Y-90. In addition, Cs-134 and Cs-137 are present in low concentrations ${ }^{1)}$, which can be measured relatively easily due to the emission of $\gamma$-rays. However, $\beta$-ray-emitting nuclides such as $\mathrm{Sr}-90$ generally require complicated chemical separation and advanced measurement techniques ${ }^{2-4)}$ as well as a long time for analysis.

* Corresponding author, E-mail: kenjiro.kondo@kek.jp

DOI : 10.15669 /fukushimainsights.Vol.4.401

(C) 2021 Atomic Energy Society of Japan. All rights reserved.

Originally published in Transactions of the Atomic Energy Society of Japan (ISSN 1347-2879), Vol. 14, No. 3, p.151-160

(2015) in Japanese. (Japanese version accepted: April 9, 2015) 
Among the nuclides present in contaminated water, Sr-90 is one of the most important in terms of radiation safety management as the effluent standard prescribed under the law is as low as $0.03 \mathrm{~Bq} / \mathrm{cm}^{3}$. The provisional effluent standard to be observed for Sr-90 when discharging the stagnant water from the weir, such as a tank for storing contaminated water, at the $1 \mathrm{~F}$ power station is $0.01 \mathrm{~Bq} / \mathrm{cm}^{3}$. Therefore, a method that facilitates this concentration level to be measured easily, quickly and accurately must be developed.

In this study, low concentrations of Sr-90 were determined easily by measuring the $\beta$-rays from Y-90, concentrated and captured in a filter, using the carbonate precipitation and iron coprecipitation methods ${ }^{7,8)}$ (hereinafter referred to as "filter method").

The determination of the concentration of Sr-90 by the filter method involves the precipitation and concentration of Sr-90 or Y-90 in a filter through simplified chemical separation and subsequent measurement with a GM instrument used in the radiation management field, without requiring advanced radiochemical separation of Sr-90 or Y-90. This method was found to contribute to the efficiency of management of contaminated water at the $1 \mathrm{~F}$ power station.

\section{Water Samples to be Examined and Outline of Filter Method}

\section{Water Samples to be Examined}

Table 1 shows the major radionuclides present in RO-concentrated salt water (concentrated salt water with RO (Reverse Osmosis) membrane) stored in the $\mathrm{H} 1 \operatorname{tank}^{9)}$ (This is a facility (equipment) at the $1 \mathrm{~F}$ power station in which high concentrations of $\mathrm{Sr}-90 / \mathrm{Y}-90$ are present), H4-No.5 tank ${ }^{1)}$, and underground water (No. 1-4 observation wells) ${ }^{10)}$ as well as their concentrations, as an example of the radionuclides and their concentrations to be measured in the water sample from the 1F power station. Table 2 shows the nuclear characteristics of such nuclides ${ }^{11)}$. The proposed method of measurement is intended for water samples with relatively low concentrations of radioactive materials such as high-concentration contaminated water leaked from a tank and diluted with a large volume of rainwater or groundwater polluted with high-concentration contaminated water that has seeped underground. It is clear from Table 1 that the major nuclides are Sr-90 and Y-90 whereas the concentration of other nuclides such as Cs-134 and Cs-137 is lower than one hundredth of the concentration of Sr-90.

Table 1 Principal radioisotopes and their concentrations in the water sampled at the site of Fukushima Daiichi Nuclear Power Plant of Tokyo Electric Power Company

\begin{tabular}{|c|c|c|c|}
\hline Nuclide & $\begin{array}{c}\text { RO-concentrat- } \\
\text { ed salt-water } \\
\text { H1 tank }\end{array}$ & $\begin{array}{l}\text { RO-concentrat- } \\
\text { ed solt-water } \\
\text { H4-No.5 tank }{ }^{1)}\end{array}$ & $\begin{array}{l}\text { Underground } \\
\text { water (No.1-4 } \\
\text { observation } \\
\text { point) }{ }^{10)}\end{array}$ \\
\hline & \multicolumn{3}{|c|}{$\mathrm{Bq} / \mathrm{cm}^{3}$} \\
\hline $\mathrm{Mn}-54$ & & $1.9 \mathrm{E}+00$ & \\
\hline $\mathrm{Co}-60$ & & $1.2 \mathrm{E}+00$ & \\
\hline $\mathrm{Sr}^{-}-90$ & $7.6 \mathrm{E}+04$ & & \\
\hline $\mathrm{Cs}^{-134}$ & $4.7 \mathrm{E}+01$ & $4.6 \mathrm{E}+01$ & $1.0 \mathrm{E}-03$ \\
\hline $\mathrm{Cs}^{-137}$ & $6.6 \mathrm{E}+01$ & $1.0 \mathrm{E}+02$ & $1.1 \mathrm{E}-02$ \\
\hline Total $\beta$ & $3.9 \mathrm{E}+05$ & $8.0 \mathrm{E}+04$ & $2.4 \mathrm{E}-01$ \\
\hline
\end{tabular}


Table 2 Principal radioisotopes in the water sample and their nuclear characteristics

\begin{tabular}{|c|c|c|c|c|c|c|}
\hline Nuclide & Half-life & Decay mode & $\begin{array}{c}\text { Maximum } \beta \text { ray } \\
\text { Energy }(\mathrm{MeV})\end{array}$ & Eemission rate & $\begin{array}{c}\text { Main } \gamma \text { ray energy } \\
(\mathrm{MeV})\end{array}$ & Emission rate \\
\hline${ }^{54} \mathrm{Mn}$ & $312.03 \mathrm{~d}$ & $\mathrm{EC}$ & & 1.0 & 0.836 & 1.0 \\
\hline \multirow{2}{*}{${ }^{60} \mathrm{Co}$} & \multirow{2}{*}{$5.2713 \mathrm{y}$} & \multirow{2}{*}{$\beta^{-}$} & 0.318 & 0.999 & 1.173 & 0.999 \\
\hline & & & 1.491 & 0.0012 & 1.333 & 1.0 \\
\hline \multirow{2}{*}{$\begin{array}{l}{ }^{90} \mathrm{Sr} \\
{ }^{90} \mathrm{Y}\end{array}$} & $28.79 \mathrm{y}$ & $\beta^{-}$ & 0.546 & 1.0 & & \\
\hline & $64.00 \mathrm{~h}$ & $\beta^{-}$ & 2.28 & 1.0 & & \\
\hline \multirow{7}{*}{${ }^{134} \mathrm{Cs}$} & \multirow{7}{*}{$2.065 \mathrm{y}$} & \multirow{7}{*}{$\beta^{-}$} & 0.0888 & 0.273 & 0.563 & 0.084 \\
\hline & & & 0.415 & 0.025 & 0.569 & 0.154 \\
\hline & & & 0.658 & 0.702 & 0.605 & 0.976 \\
\hline & & & \multirow[t]{4}{*}{ Others } & & 0.796 & 0.866 \\
\hline & & & & & 0.802 & 0.087 \\
\hline & & & & & 1.365 & 0.03 \\
\hline & & & & & Others & \\
\hline \multirow{2}{*}{${ }^{137} \mathrm{Cs}$} & \multirow{2}{*}{$30.1671 \mathrm{y}$} & \multirow{2}{*}{$\beta^{-}$} & 0.514 & 0.944 & & \\
\hline & & & 1.176 & 0.056 & & \\
\hline${ }^{137 \mathrm{~m}} \mathrm{Ba}$ & $2.532 \mathrm{~m}$ & IT & & & 0.662 & 0.851 \\
\hline
\end{tabular}

\section{Outline of Filter Method}

In this method, Sr-90 and Y-90 are separated and concentrated in a filter using the carbonate precipitation and iron coprecipitation methods, and the filter is then used as a measurement sample. A polyethylene plate is inserted between the filter and GM counter tube as a $\beta$-ray absorber, and only those $\beta$-rays emitted with high energy are measured to determine the concentration of Y-90. If Sr-90 and Y-90 are confirmed to have achieved a state of secular equilibrium, the concentration of Y-90 obtained in a measurement is considered to be that of Sr-90 as well; otherwise the measurement is conducted twice after a certain interval to evaluate the concentration of Sr-90 based on the sequential decay relation between Sr-90 and Y-90.

\section{(1) Selective measurement of $\beta$-rays from Y-90 using a $\beta$-ray absorber}

Figure 1 shows the number of electrons which pass through the polyethylene plate $(1 \mathrm{~mm}$ is equivalent to $0.090 \mathrm{~g} / \mathrm{cm}^{2}$ ) and enter the GM counter, which is calculated using the electromagnetic cascade Monte Carlo calculation code egs $5^{12}$, when Sr-90, Y-90, Cs-134, Cs-137, and Co-60 are present on the filter surface with an areal density of $1 \mathrm{~Bq} / \mathrm{cm}^{2}$. The $\beta$-ray spectra of the respective nuclides are used in the calculation, and the secondary electrons generated due to the scattering of $\beta$-rays, as well as those generated by bremsstrahlung radiation, are included in the result. The system of calculation is based on the layout of the measuring instruments used in this method. As shown in the figure, the insertion of a polyethylene plate of appropriate thickness enables the removal of most of the $\beta$-rays from Co-60, Sr-90, Cs-134, and Cs- 137 to selectively measure only the $\beta$-rays from Y-90.

Although based on the premise that these nuclides are present in the same concentration, the contribution of other nuclides to the $\beta$-rays from Y-90 is $8.7 \%$ when the thickness of the polyethylene plate is $1 \mathrm{~mm}$ and $0.9 \%$ when it is $2 \mathrm{~mm}$. The contribution of the $\beta$-rays can be ignored when the thickness of the polyethylene plate is $10 \mathrm{~mm}$. With a 10 -mm-thick acrylic plate of higher density than polyethylene (Density: $1.20 \mathrm{~g} / \mathrm{cm}^{2}$ ), the contribution of the $\gamma$-rays from Cs-134 and Cs-137 can be estimated as described in a later section.

In the measurement of the $\beta$-rays emitted by Y-90, Sr-89, which is an isotope of $\mathrm{Sr}$ (Halflife: 50.5 days, maximum $\beta$-ray energy: $1.49 \mathrm{MeV}$ ), is considered to be significant because of its high $\beta$-ray energy, however, as more than three years have elapsed since the accident, its 


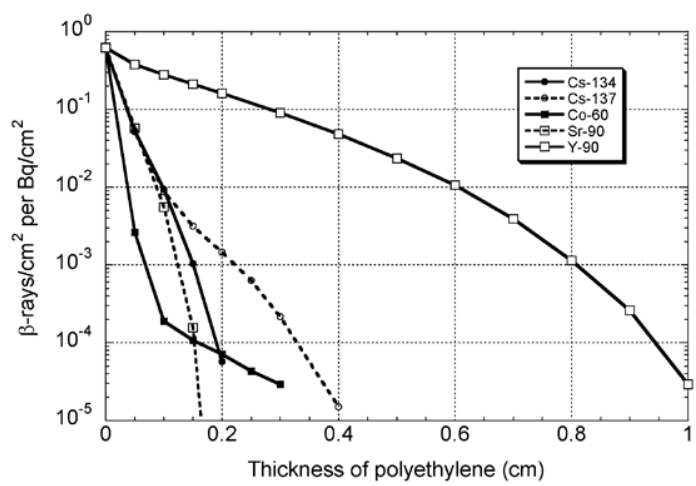

Figure 1 Relationship between thickness of polyethylene absorbers and transmission probability of $\beta$-rays from Sr-90, Y-90, Cs-134, Cs-137 and Co-60 calculated with egs5 Monte Carlo code

contribution can be ignored owing to its decay. Assuming that the contribution of Rh-106 and Ce-144, which also emit high-energy $\beta$-rays, may be ignored, a method that measures $\beta$-rays from Y-90 was used.

\section{(2) Evaluation of the radioactive concentration of $\mathrm{Sr}-90$}

This method involves the measurement of $\beta$-rays from Y-90 by concentrating and collecting the Sr-90 and Y-90 present in the water sample in a filter, regardless of the achievement of radiative equilibrium between these substances. The radioactive concentration of $\mathrm{Sr}-90$ can be determined from that of Y-90, which is measured using the polyethylene plate (with a thickness of $1 \mathrm{~mm}$ or $2 \mathrm{~mm}$ ) as a $\beta$-ray absorber. If Sr-90 and Y-90 have already achieved a state of secular equilibrium, the concentration of Sr-90 can be obtained by means of a single measurement, otherwise two measurements must be made at an interval of approximately five hours.

Assuming that the number of atoms of Sr-90 and Y-90 per $\mathrm{cm}^{3}$ when time $t$ is zero are $N_{S r-90}(0)$ and $N_{Y-90}(0)$, respectively, the number of atoms of $N_{Y-90}(t)$ after $t$ hours is determined as follows:

$$
N_{Y-90}(t)=\frac{\lambda_{S r-90}}{\lambda_{Y-90}-\lambda_{S r-90}} \times N_{S r-90}(0)\left[\exp \left(-\lambda_{S r-90} t\right)-\exp \left(-\lambda_{Y-90} t\right)\right]+N_{Y-90}(0) \exp \left(-\lambda_{Y-90} t\right)
$$

where, $\lambda_{S r-90}$ and $\lambda_{Y-90}$ are the decay constants of Sr-90 and Y-90, respectively. As $\lambda_{Y-90}-\lambda_{S r-90} \approx$ $\lambda_{Y-90}$ because $\lambda_{Y-90} \gg \lambda_{S r-90}$,

$$
\begin{aligned}
A_{Y-90}(t) & =\lambda_{Y-90} N_{Y-90}(t) \\
& =\lambda_{S r-90} N_{S r-90}(0)\left[\exp \left(-\lambda_{S r-90} t\right)-\exp \left(\lambda_{Y-90} t\right)\right]+\lambda_{Y-90} N_{Y-90}(0) \exp \left(-\lambda_{Y-90} t\right) \\
& =A_{S r-90}(0)\left[\exp \left(-\lambda_{S r-90} t\right)-\exp \left(-\lambda_{Y-90} t\right)\right]+A_{Y-90}(0) \exp \left(-\lambda_{Y-90} t\right)
\end{aligned}
$$

where, $A_{Y-90}(0)$ and $A_{Y-90}(t)$ are the radioactive concentrations of Y-90 $\left(\mathrm{Bq} / \mathrm{cm}^{3}\right)$ when time $t$ is zero and $t$, respectively, and $A_{S r-90}(0)$ is the radioactive concentration of S-90 $\left(\mathrm{Bq} / \mathrm{cm}^{3}\right)$ when time $t$ is zero. The radioactive concentration of Sr-90 can be determined by using Eq. (3) given below:

$$
A_{S r-90}(0)=\frac{A_{Y-90}(t)-A_{Y-90}(0) \exp \left(-\lambda_{Y-90} t\right)}{\exp \left(-\lambda_{S r-90} t\right)-\exp \left(-\lambda_{Y-90} t\right)}
$$

$A_{Y-90}(t)$ and $A_{Y-90}(0)$ can be obtained from the correlation (conversion coefficient) between 
the count rate of Y-90 obtained experimentally with the GM counter tube and the radioactive concentration of $\mathrm{Y}-90\left(\mathrm{~Bq} / \mathrm{cm}^{3}\right)$.

\section{Points to be Considered in the Experiment}

In order to ensure the validity of the application of the filter method, the following points must be given due consideration:

a) The collection efficiency at the time of concentrating and separating the Sr-90 and Y-90 from the water samples into the filter using the carbonate precipitation and iron coprecipitation methods.

b) The correlation between the count rate of Y-90 measured with a GM detector and radioactive concentration of Y-90 and Sr-90 using a standard Sr-90 solution (conversion coefficient).

c) The influence of seawater content, due to a possible incorporation of seawater into some water samples collected at the $1 \mathrm{~F}$ power station, on $\mathrm{Y}-90$ measurements.

d) Using the polyethylene plate as a $\beta$-ray absorber enables the measurement of the $\beta$ rays of Y-90 only, however, a GM detector has the sensitivity to detect $\gamma$-rays and bremsstrahlung radiation. Therefore, the influence of the $\gamma$-rays from the nuclides such as Cs- 134 and Cs-137, which are present in the water samples, as well as the bremsstrahlung radiation from $\beta$-rays on the measurement of Y-90, must be considered.

The experiment was conducted in view of the above-mentioned points and the results are described in the next section.

\section{Experiment and Results}

\section{Concentration, Separation and Collection Efficiencies with a Filter}

\section{(1) Separation and collection of $\mathrm{Sr}$ and $\mathrm{Y}$}

Considering that Sr-90 and Y-90, which are close to the carrier-free state, are present in the water samples collected from $1 \mathrm{~F}$ power station, $\mathrm{Sr}$ and $\mathrm{Y}$ were added as carriers in advance to study the separation conditions and the collection efficiencies of $\mathrm{Sr}$ and $\mathrm{Y}$ were determined using the carbonate precipitation and iron coprecipitation methods.

In this method, $\mathrm{Sr}$ and $\mathrm{Y}$ are separated as strontium carbonate and yttrium hydroxide, respectively. $\mathrm{Fe}^{3+}$ ions are added to facilitate the processes of sedimentation and separation due to the coprecipitation effect. As the water samples that are collected from the $1 \mathrm{~F}$ power station also contain Cs-134 and Cs-137 in the carrier-free state, Cs with a similar concentration as $\mathrm{Sr}$ is added as a carrier for the separation operation when conducting the process with actual water samples.

\section{(2) Preparation of water samples used in the experiment}

The water samples used in the experiment contained pure water, seawater, and well water collected from the High Energy Accelerator Research Organization (This was prepared by sterilizing the ground water to render it potable and is hereinafter referred to as "well water"). The well water was used as simulated groundwater obtained from the $1 \mathrm{~F}$ power station, and the water samples containing seawater were used to study the influence of the incorporation of seawater on the measurements because it was possible that seawater was mixed with some water samples collected from the $1 \mathrm{~F}$ power station. The chemicals used for calibration in the sedimentation, separation, and inductively coupled plasma (ICP) emission spectrometric 
analyses are given below:

Standard $\mathrm{Sr}^{2+}$ and $\mathrm{Y}^{3+}$ atomic absorption solutions (Kishida Chemical Co., Ltd.) containing $1,000 \mathrm{ppm}$ of $\mathrm{Sr}^{2+}$ or $\mathrm{Y}^{3+}, \mathrm{Fe}^{3+}$ prepared by mixing special grade ferric chloride (Junsei Chemical Co., Ltd.) with $0.1 \mathrm{~N}$ hydrochloric acid to $10 \mathrm{mg} / \mathrm{mL}$, and $\mathrm{Ca}^{2+}$ prepared by dissolving special grade $\mathrm{CaCO}_{3}$ (Junsei Chemical Co., Ltd.) with concentrated hydrochloric acid as $\mathrm{Ca}^{2+}$ to $50 \mathrm{mg} / \mathrm{mL}$. Granular $\mathrm{Na}_{2} \mathrm{CO}_{3}$ of special grade (Wako Pure Chemical Corporation) was used in the original form and artificial seawater was prepared using Daigo's Artificial Seawater SP (for one liter, Nihon Pharmaceutical Co., Ltd.).

\section{(3) Separation and collection operation procedures}

A solution of $100 \mathrm{~mL}$ of the water sample containing pure water, seawater, and well water was prepared by adjusting the $\mathrm{Fe}^{3+}$ concentration to $50 \mathrm{ppm}, \mathrm{Sr}^{2+}$ and $\mathrm{Y}^{3+}$ concentrations to $10 \mathrm{ppm}$ using standard solutions, and $\mathrm{Ca}^{2+}$ concentration to $250 \mathrm{ppm}$ from the prepared $\mathrm{Ca}$ solution. This solution was agitated and then heated to approximately $50^{\circ} \mathrm{C}$. After one gram of $\mathrm{Na}_{2} \mathrm{CO}_{3}$ was added, the solution was agitated vigorously with a magnetic stirrer for approximately seven minutes and then agitated gently for approximately three minutes to promote the generation of a deposit and formation of floc. The solution was subsequently left to rest for approximately three minutes for the deposit to settle at the bottom in the form of floc and then filtrated. A filtering device with a 47-mm filter holder made entirely of glass (Nihon Millipore) was used. In order to ensure the uniformity of deposition, the supernatant was first filtered and when the volume was reduced to almost half, the rest of the solution was poured into a funnel. Normally, the filtration time is approximately $30 \mathrm{~s}$. The membrane filter used was a mixed cellulose ester filter (Millipore Advantec) with a pore size of $0.65 \mu \mathrm{m}$ and diameter of $47 \mathrm{~mm}$. The filtration was carried out while reducing the pressure with an aspirator and the suction was terminated when water stopped dripping from the filter. The concentrations of $\mathrm{Sr}$ and $\mathrm{Y}$ present in the undiluted solution before addition of $\mathrm{Na}_{2} \mathrm{CO}_{3}$ and the filtered solution were measured by the ICP emission spectrometric analysis method to determine the collection efficiencies of $\mathrm{Sr}$ and $\mathrm{Y}$.

\section{(4) Collection efficiencies of $\mathrm{Sr}$ and $\mathrm{Y}$}

Table 3 shows the collection efficiencies of $\mathrm{Sr}$ and $\mathrm{Y}$ from the water samples containing pure water, seawater, and well water, as determined by the method proposed in this study. As a result of adding an excessive amount of $\mathrm{Ca}$ and allowing sufficient time for the reaction to take place

Table 3 Collection efficiencies of $\mathrm{Sr}$ and $\mathrm{Y}$

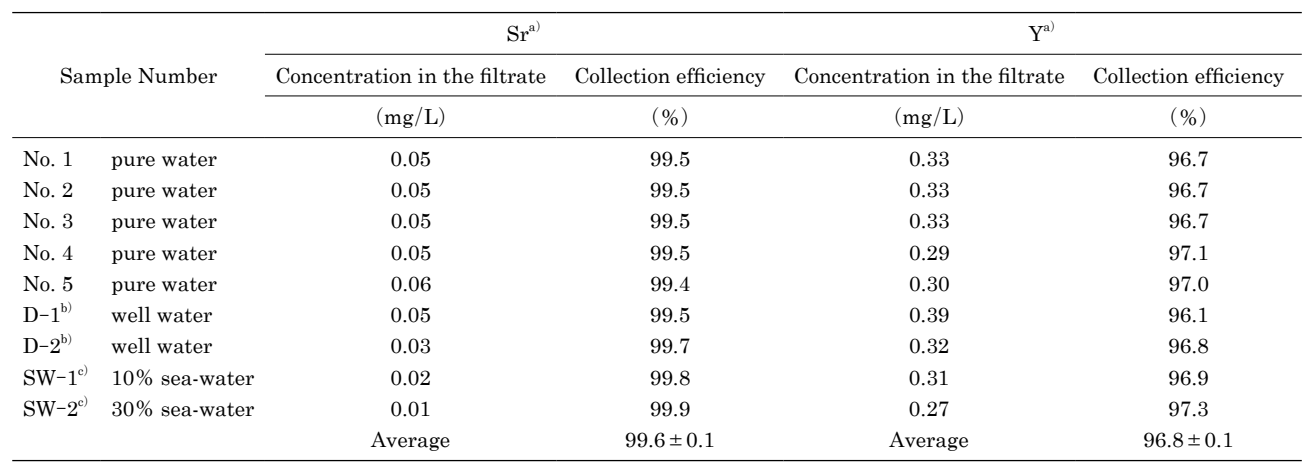

Concentration of $\mathrm{Sr}$ and/or $\mathrm{Y}$ in the start solution: $10.0 \mathrm{mg} / \mathrm{L}$

Well water: $\mathrm{Mg}^{2+}: 7 \mathrm{ppm}, \mathrm{Ca}^{2+}: 19 \mathrm{ppm}, \mathrm{Na}^{+}: 31 \mathrm{ppm}, \mathrm{K}^{+}: 4 \mathrm{ppm}, \mathrm{Cl}^{-}: 49 \mathrm{ppm}, \mathrm{SO}_{4}{ }^{2-}: 2-25 \mathrm{ppm}, \mathrm{Br}^{-}: 1 \mathrm{ppm} . \mathrm{pH}: 7.6$

Water containing seawater 
and maturation of the deposit, the collection efficiencies of $\mathrm{Sr}$ and $\mathrm{Y}$ were found to be $99.6 \%$ and $96.8 \%$, respectively. It was demonstrated that the $\mathrm{Sr}$ and $\mathrm{Y}$ in the water samples containing pure water, seawater, and well water were concentrated and captured in the filter at high collection efficiency and with high reproducibility. This result shows that the Sr-90 and Y-90 present in the stagnant water in the weir of the contaminated water tank and water samples containing underground water and seawater can be deposited and separated with high collection efficiency.

\section{Correlation between the Count rates of Y-90 and Radioactive Concentrations of Sr-90 and Y-90 (Conversion Coefficient)}

\section{(1) Concentration/Separation and radioactivity measurement of Sr-90 and Y-90 using a standard Sr-90 solution}

The relation between the count rates obtained with a GM detector and the radioactive concentrations of Sr-90 and Y-90 (conversion coefficient) was studied, where the measurement sample was the filter obtained by conducting the deposition and separation processes with the pure water-based sample containing Sr-90 of known concentration.

(a) Adjustment and concentration/collection of water samples containing Sr-90

The solutions were prepared with a concentration of $0.31 \mathrm{kBq} / \mathrm{mL}(50 \mathrm{~mL}$ measuring flask) and $3.1 \mathrm{~Bq} / \mathrm{mL}$ (100 mL measuring flask), with a standard Sr-90 solution (Eckert \& Ziegle) $\mathrm{SrCl}_{2} 0.1 \mathrm{M} \mathrm{HCl}, 15.5 \pm 0.4 \mathrm{kBq} / 5 \mathrm{~mL}$, and the specified amount from these solutions was added to adjust the concentration of Sr-90.

After adding the carriers to $100 \mathrm{~mL}$ of pure water containing Sr-90 of known concentration as described above, the deposition and separation of Sr-90 and Y-90 was carried out following the same procedure. At the $1 \mathrm{~F}$ power station, a simplified method of measurement ${ }^{13)}$ is adopted with a $500 \mathrm{~mL}$ sample water for measuring low-concentration $\mathrm{Sr}-90$, when it is imperative to determine whether the stagnant water in the weir of the RO-concentrated salt water storage tank can be discharged or not. In this study, lowering the measurable concentration by using a $400 \mathrm{~mL}$ water sample was also studied. In this case, the amount of chemicals added, except for the standard Sr-90 solution, should be four times as large as those added to $100 \mathrm{~mL}$ water samples, and the operations such as separation must be carried out according to the same procedures as the ones used for the $100 \mathrm{~mL}$ water samples. Assuming that Sr-90 and Y-90 in the standard solution achieved secular equilibrium, the analysis was conducted as described below:

(b) Measuring filter and radioactive measurement

The filter which was used in the collection process was sealed with a transparent laminate coating film. In addition, it was sealed in a polyethylene bag. Furthermore, it was placed between two plastic plates with $50 \mathrm{~mm}$ opening $(0.5 \mathrm{~mm}$ thick) for fixation. This opening was as large as the window of the GM counter tube. The size of the deposit was $37 \mathrm{~mm}$ in diameter. The center of the filter was aligned with the center of the GM counter tube and after securing it to the measuring stand the GM counter tube (Hitachi Aloka Medical, Ltd., GM survey meter TGS-146B ${ }^{14)}$ ) was firmly attached to conduct the measurement. In addition, after attaching the polyethylene plates ( $1 \mathrm{~mm}$ and $2 \mathrm{~mm}$ thick) as well as a $10-\mathrm{mm}$-thick acrylic plate $\left(1.20 \mathrm{~g} / \mathrm{cm}^{2}\right)$ close to the filter, the GM counter tube was firmly attached on top of them to conduct the measurements. The weight per unit area with the laminate coating film and polyethylene bag was approximately $0.0001 \mathrm{~g} / \mathrm{cm}^{2}$. The radioactive measurement was carried out in a box shielded with 5 -cm-thick lead. The background with no measurement sample was $0.45 \pm 0.1 \mathrm{cps}$. For the low-concentration sample, a three-minute measurement was conducted three times and for other samples, a one-minute measurement was conducted three times to determine the average 
value. The correction for the measurements was made based on a dead time of $250 \mu \mathrm{sec}$.

\section{(2) Conversion coefficient}

The results of the measurements with water samples of $100 \mathrm{~mL}$ and $400 \mathrm{~mL}$, classified into three types according to the low to high radioactive concentration range of $\mathrm{Sr}-90$ are shown in Figures 2 and 3. In the measurements using 1-mm and 2-mm $\beta$-ray absorbers, the count rates are based on the $\beta$-rays from Y-90 and the corresponding concentration is the radioactive concentration of Y-90, which is the same as the radioactive concentration of Sr-90 as it has achieved a state of secular equilibrium.

The measurements of the $\beta$-rays from Sr-90 and Y-90 were conducted directly with the filter (with no polyethylene plate) and these correspond to the radioactive concentration of Sr-90 and Y-90. For the $100 \mathrm{~mL}$ water sample, the measurement was conducted with and without the polyethylene plates $1 \mathrm{~mm}$ and $2 \mathrm{~mm}$ thick (the polyethylene plate $1 \mathrm{~mm}$ thick was $0.090 \mathrm{~g} / \mathrm{cm}^{2}$ ), and superior linearity was observed in the count rates and concentrations of Sr-90 and Y-90 at a concentration of approximately $0.03 \mathrm{~Bq} / \mathrm{cm}^{3}$ (effluent standard prescribed by law) or higher. In addition, in the case of measurements with the $400 \mathrm{~mL}$ water sample conducted in order to study the measurability of lower concentrations, superior linearity was observed in the count rates of radioactivity collected in the filter as well as the radioactive concentrations of Sr-90 and Y-90 in a wide range of concentrations at approximately $0.005 \mathrm{~Bq} / \mathrm{cm}^{3}$ or higher, as shown in Figure 3. At the 400-mL level, the sensitivity for detecting the radioactive concentrations that were much lower than the provisional effluent standard currently being used $\left(0.01 \mathrm{~Bq} / \mathrm{cm}^{3}\right)$ was confirmed, showing that the proposed method can be applied to low concentrations at around this level.

The deposits were collected in a $37 \mathrm{~mm}$ filter in diameter. The influence of self-absorption due to the amount of deposits was found to be small because high-energy $\beta$-rays from Y-90 were measured. The error bars in the figure correspond to the standard deviation $(1 \sigma)$ when the background is deducted. Table 4 shows the conversion coefficients and residual sums of squares $\left(\chi^{2}\right)$ determined by the least squares method based on the relation between the count rates (cps) and the radioactive concentrations of Sr-90 and Y-90 (Bq/ $\left.\mathrm{cm}^{3}\right)$ in the low concentration, medium concentration, and entire concentration ranges, according to the radioactive concentrations of Sr-90 used. The conversion coefficients differ depending on the thickness of the polyethylene plate and amount of water sample. As shown in Table 4, the conversion coefficients show a superior concordance in the concentration ranges of $0.5 \mathrm{~Bq} / \mathrm{cm}^{3}$ or lower as well as $6 \mathrm{~Bq} / \mathrm{cm}^{3}$ or lower in the case of $100 \mathrm{~mL}$ water samples and in the concentration ranges of $0.3 \mathrm{~Bq} / \mathrm{cm}^{3}$ or lower as well as $1 \mathrm{~Bq} / \mathrm{cm}^{3}$ or lower in the case of $400 \mathrm{~mL}$ water samples. On the other hand, they are slightly smaller in the concentration range of $0.05 \mathrm{~Bq} / \mathrm{cm}^{3}$ or lower in the case of $100 \mathrm{~mL}$ water samples and in the concentration range of $0.03 \mathrm{~Bq} / \mathrm{cm}^{3}$ or lower in the case of $400 \mathrm{~mL}$ water samples. In actual measurement, the concentration of Y-90 (or Sr-90) is evaluated using the conversion coefficient obtained for the entire concentration range with many measuring points. However, in the low concentration range, there is an overestimation of approximately $15 \%$ and $10 \%$ for the $100 \mathrm{~mL}$ and $400 \mathrm{~mL}$ water samples, respectively, when a $2 \mathrm{~mm}$-thick polyethylene plate is used. It is preferable that a polyethylene plate with a thickness of $2 \mathrm{~mm}$ is used in the measurement from the perspective that the concentration of substances such as radioactive $\mathrm{Cs}$, which are present in the deposits collected in the filter, changes significantly and only the $\beta$-rays from Y-90 are measured, even though the properties of the water sample are unknown. 


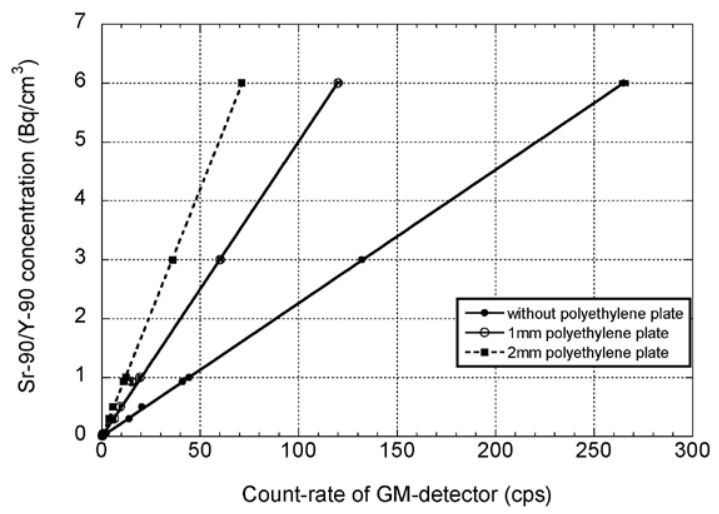

(a) the entire region of concentration: $\leq 6 \mathrm{~Bq} / \mathrm{cm}^{3}$

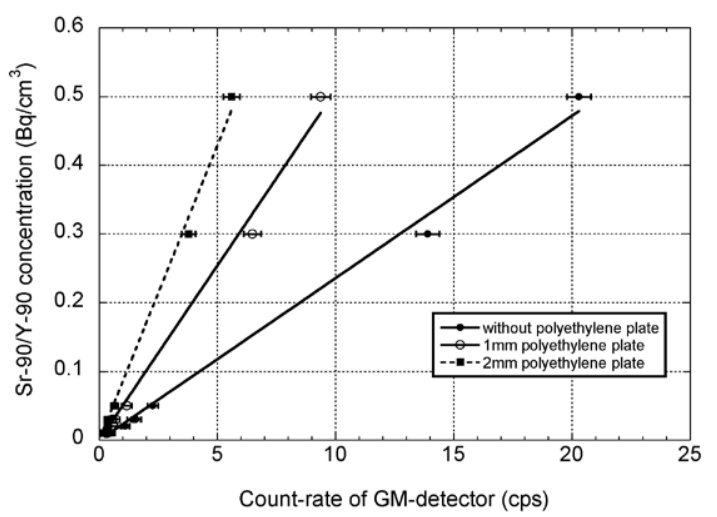

(b) the part of low concentration: $\leq 0.5 \mathrm{~Bq} / \mathrm{cm}^{3}$

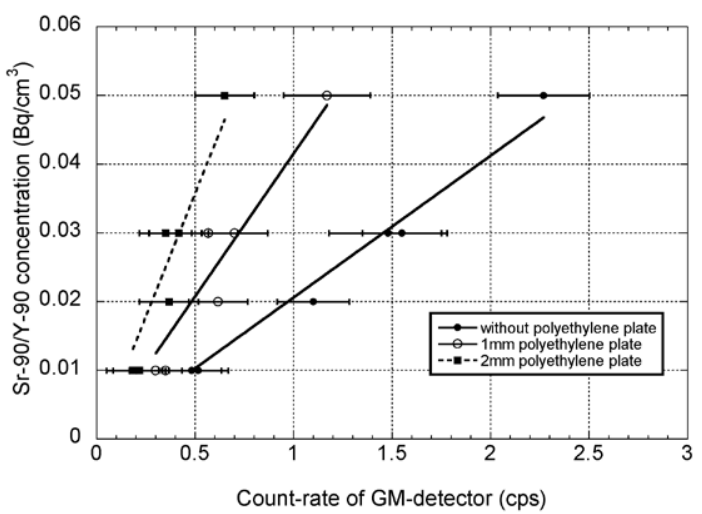

(c) the part of low concentration: $\leq 0.05 \mathrm{~Bq} / \mathrm{cm}^{3}$

Figure 2 Relationship between concentrations of $\mathrm{Sr}-90 / \mathrm{Y}-90\left(\mathrm{~Bq} / \mathrm{cm}^{3}\right)$ and count rates of GM-detector (water volume: $100 \mathrm{~mL}$, absorber: polyethylene plate)

(a) the entire region with a concentration: $\leq 6 \mathrm{~Bq} / \mathrm{cm}^{3}$

(b) the part with a low concentration: $\leq 0.5 \mathrm{~Bq} / \mathrm{cm}^{3}$

(c) the part with a low concentration: $\leq 0.05 \mathrm{~Bq} / \mathrm{cm}^{3}$ 


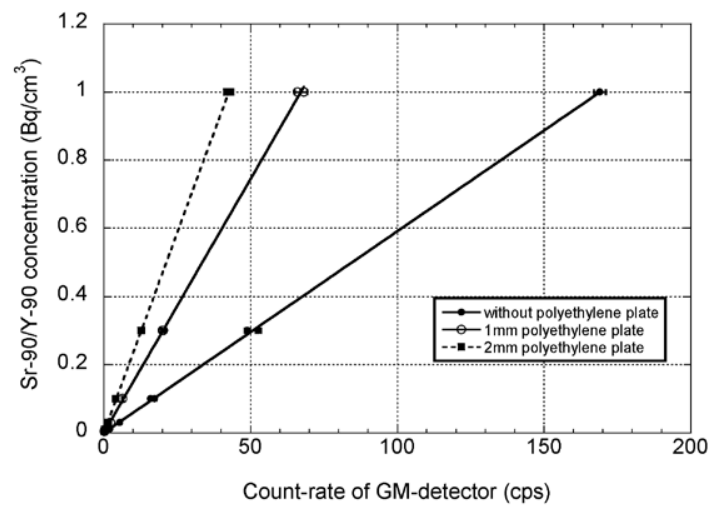

(a) the entire region of concentration: $\leq 1 \mathrm{~Bq} / \mathrm{cm}^{3}$

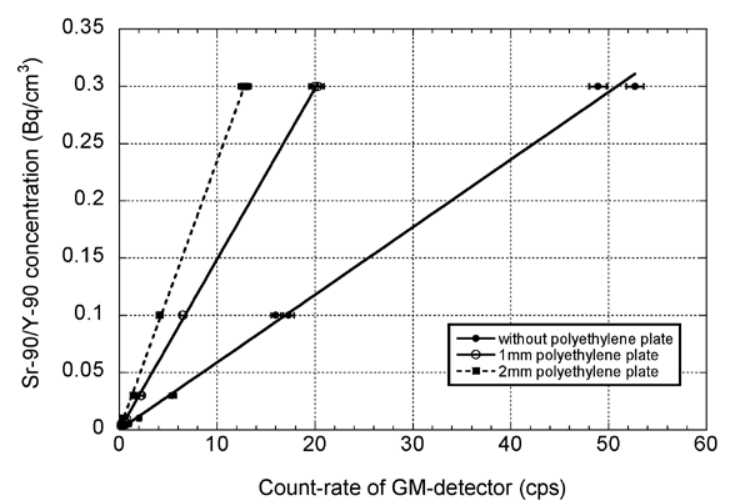

(b) the part of low concentration: $\leq 0.3 \mathrm{~Bq} / \mathrm{cm}^{3}$

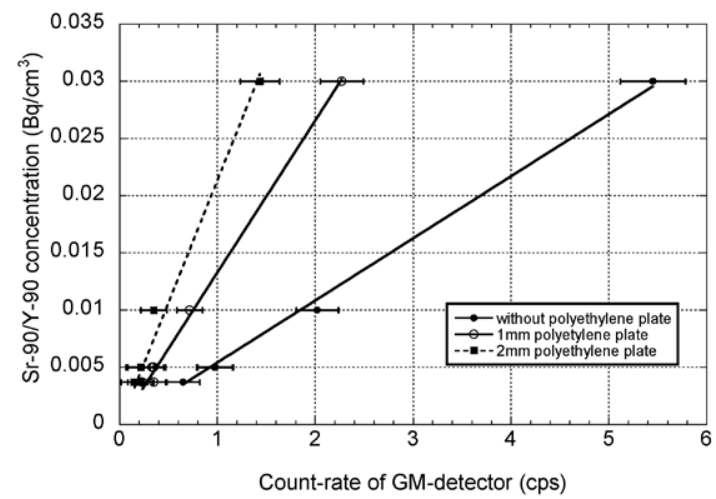

(c) the part of low concentration: $\leq 0.03 \mathrm{~Bq} / \mathrm{cm}^{3}$

Figure 3 Relation between concentrations of Sr-90/Y-90 (Bq/ $\mathrm{cm}^{3}$ ) and count rates of GM-detector (water volume: $400 \mathrm{~mL}$, absorber: polyethylene plate)
(a) the entire region with a concentration: $\leq 1 \mathrm{~Bq} / \mathrm{cm}^{3}$
(b) the part with a low concentration: $\leq 0.3 \mathrm{~Bq} / \mathrm{cm}^{3}$
(c) the part with a low concentration: $\leq 0.03 \mathrm{~Bq} / \mathrm{cm}^{3}$

\section{Influence of Seawater Concentration on the Measurements of Y-90}

As in the case for pure water, high collection efficiency was achieved in the case of well water, as shown in Table 3 (The component analysis result is shown in the Note of Table 3 ). 
Table 4 Conversion co-efficiencies of $\mathrm{cps}$ to $\mathrm{Bq} / \mathrm{cm}^{3}$

\begin{tabular}{|c|c|c|c|c|c|c|c|}
\hline \multirow{2}{*}{ Sample volume } & \multirow{2}{*}{$\begin{array}{l}\text { Polyethylene } \\
\text { plate thickness } \\
\text { mm }\end{array}$} & \multicolumn{6}{|c|}{ Conversion co-efficient } \\
\hline & & $\left(\mathrm{Bq} / \mathrm{cm}^{3}\right) / \mathrm{cps}$ & $\chi^{2}$ & $\left(\mathrm{~Bq} / \mathrm{cm}^{3}\right) / \mathrm{cps}$ & $\chi^{2}$ & $\left(\mathrm{~Bq} / \mathrm{cm}^{3}\right) / \mathrm{cps}$ & $\chi^{2}$ \\
\hline \multirow{4}{*}{$100 \mathrm{~mL}$ sample } & & \multicolumn{2}{|c|}{ Concentration $\leq 6 \mathrm{~Bq} / \mathrm{cm}^{3}$} & \multicolumn{2}{|c|}{ Concentration $\leq 0.5 \mathrm{~Bq} / \mathrm{cm}^{3}$} & \multicolumn{2}{|c|}{ Concentration $\leq 0.05 \mathrm{~Bq} / \mathrm{cm}^{3}$} \\
\hline & 0 & 0.0227 & 0.00201 & 0.0236 & 0.00135 & 0.0206 & $2.19 \mathrm{E}-05$ \\
\hline & 1 & 0.0502 & 0.0329 & 0.0509 & 0.00177 & 0.0416 & 0.000103 \\
\hline & 2 & 0.0842 & 0.00540 & 0.0859 & 0.00128 & 0.0716 & 0.000116 \\
\hline \multirow{4}{*}{$400 \mathrm{~mL}$ sample } & & \multicolumn{2}{|c|}{ Concentration $\leq 1 \mathrm{~Bq} / \mathrm{cm}^{3}$} & \multicolumn{2}{|c|}{ Concentration $\leq 0.3 \mathrm{~Bq} / \mathrm{cm}^{3}$} & \multicolumn{2}{|c|}{ Concentration $\leq 0.03 \mathrm{~Bq} / \mathrm{cm}^{3}$} \\
\hline & 0 & 0.00592 & 0.000297 & 0.00590 & 0.000297 & 0.00543 & $1.34 \mathrm{E}-06$ \\
\hline & 1 & 0.0149 & 0.000588 & 0.0149 & $4.98 \mathrm{E}-05$ & 0.0133 & $1.97 \mathrm{E}-06$ \\
\hline & 2 & 0.0235 & 0.000521 & 0.0235 & $5.44 \mathrm{E}-05$ & 0.0214 & $8.13 \mathrm{E}-06$ \\
\hline
\end{tabular}

Therefore, this would indicate that this method can be applied to most of the underground water obtained from the $1 \mathrm{~F}$ power station. Moreover, although seawater was considered to be incorporated in some water samples to be measured, high collection efficiency was also achieved for seawater concentrations of $10 \%$ and $30 \%$ as shown in Table 3, which signifies that this measurement method can be applied to seawater. However, deposits accumulate in the water samples containing seawater, and the influence of self-absorption due to such deposits must be taken into account. As a result, the influence of concentration of seawater on the measurements of Y-90 in this filter method was studied.

Using artificial seawater, $100 \mathrm{~mL}$ water samples were prepared with concentrations of 1, 2, 3, $7,10,15,20$, and $30 \%$. Carriers were added to these water samples, as in the aforementioned experiment, to prepare solutions with a Sr-90 concentration of $1.0 \mathrm{~Bq} / \mathrm{cm}^{3}$. The filter was examined after conducting the deposition and separation processes with these solutions, according to the aforementioned method. The deposits in the samples containing seawater were bulky and wet, as compared to the deposits in the $100 \mathrm{~mL}$ water sample with a seawater concentration of $0 \%$.

Table 5 shows the results of the measurement as well as the ratios of the count rates to that when the seawater concentration was $0 \%$ with a $2-\mathrm{mm}$-thick polyethylene plate. In addition to the effect of the seawater content, an increase in the amount of deposits, due to substances such as $\mathrm{Mg}$ present in the seawater, was considered to be significant. At seawater concentrations from $7 \%$ to $30 \%$, the ratio of the count rate to that when the seawater concentration was $0 \%$ was almost constant (nearly 0.86 ). If the seawater concentration is unknown, the concentration that is determined, using the count rate and conversion coefficient of Y-90 shown in Table 4 (for the total concentration range), is underestimated. If it is apparent that water sample contains seawater, the concentration of Y-90 can be estimated by using the value obtained on multiplying the count rate of Y-90 by 1.16 . However, a slight overestimation would occur at seawater concentrations of $7 \%$ or lower.

The deposits in seawater samples were susceptible to moisture, and the weight of the seawater with a concentration of $10 \%$, measured after it is dried for 24 hours in a desiccator, was $0.0042 \mathrm{~g} / \mathrm{cm}^{2}$. The actual water content of the deposits at the time of measurement was unknown, and a correlation between the amount of deposits and self-absorption was not observed.

In the actual separation process, if a water sample with a seawater concentration of $20 \%$ or higher is used, it is too difficult to conduct a quantitative measurement because the attachment of bulky deposits to the wall cannot be avoided when removing the filter and it is difficult to conduct a reproducible measurement if a water sample contains a high concentration of seawater. Therefore, in the case of such water samples, it is necessary to check the saline concentration and dilute the water sample before conducting the measurements. 
Table 5 Effect of seawater concentration on Y-90 count rates

\begin{tabular}{ccccc}
\hline \multirow{2}{*}{$\begin{array}{c}\text { Sample } \\
\text { No }\end{array}$} & $\begin{array}{c}\text { Concentra- } \\
\text { tion of Sr-90 }\end{array}$ & $\begin{array}{c}\text { Cocentra- } \\
\text { tion of sea } \\
\text { water }\end{array}$ & $\begin{array}{c}\text { Count-rate } \\
\text { with } 2 \mathrm{~mm} \\
\text { polyethylene }\end{array}$ & $\begin{array}{c}\text { Ratio to } \\
\text { A }\end{array}$ \\
\cline { 2 - 5 } & $\mathrm{Bq} / \mathrm{cm}^{3}$ & $\%$ & $\mathrm{cps}$ & $\mathrm{B} / \mathrm{A}$ \\
\hline No. S-0 & 1 & 0 & $12 \pm 0.5(\mathrm{~A})$ & - \\
No. S-1 & 1 & 1 & $11.6 \pm 0.5(\mathrm{~B})$ & 0.96 \\
No. S-2 & 1 & 2 & $11.3 \pm 0.5(\mathrm{~B})$ & 0.93 \\
No. S-3 & 1 & 3 & $11.3 \pm 0.5(\mathrm{~B})$ & 0.94 \\
No. S-4 & 1 & 7 & $10.3 \pm 0.5(\mathrm{~B})$ & 0.86 \\
No. S-5 & 1 & 7 & $10.3 \pm 0.5(\mathrm{~B})$ & 0.85 \\
No. S-6 & 1 & 10 & $10.3 \pm 0.5(\mathrm{~B})$ & 0.86 \\
No. S-7 & 1 & 15 & $10.3 \pm 0.5(\mathrm{~B})$ & 0.86 \\
No. S-8 & 1 & 20 & $10.7 \pm 0.5(\mathrm{~B})$ & 0.88 \\
No. S-9 & 1 & 30 & $10.1 \pm 0.4(\mathrm{~B})$ & 0.84 \\
\hline
\end{tabular}

\section{Influence of $\gamma$-Ray and Bremsstrahlung Radiation on the Measurements of $\gamma$-Rays from Y-90}

The GM counter tube used in the measurement is sensitive not only to $\beta$-rays but also to $\gamma$-rays and bremsstrahlung radiation (hereinafter referred to as "photon"). In the measurement of $\beta$-rays from Y-90, the influence of bremsstrahlung radiation generated by $\gamma$ - and $\beta$-rays from the nuclides contained in the water samples must be considered.

According to Figure 1, the contribution of $\beta$-rays can be ignored when an acrylic plate of thickness $10 \mathrm{~mm}\left(1.20 \mathrm{~g} / \mathrm{cm}^{2}\right)$ is used. Photons are attenuated by the $10-\mathrm{mm}$-thick acrylic plate, but the rate of attenuation caused by the acrylic plate is much lower than that caused by $\beta$-rays. This indicates that the results of measurement after passing through the 10-mm-thick acrylic plate can be used as the background measurement due to these photons. The influence of the background due to photons was studied using a standard Cs-137 planar source. In addition, according to the deposition method used in the experiment, it is considered that the rate of collection of the Cs-134 and Cs-137 in the filter is very low because most of them enter the filtrate due to their chemical properties even if they are contained in a water sample. In order to verify this, the collection efficiency was measured using a standard Cs-137 solution.

\section{(1) Evaluation of background due to Cs-137 photons}

Depending on the condition of Cs-134 and Cs-137 dissolved in the water samples from the $1 \mathrm{~F}$ power station, it is possible that some of them are collected in the filter.

Therefore, the influence of the photons from the Cs-134 and Cs-137 collected in the filter on the evaluation of the Sr-90 concentration was investigated.

In the experiment, the photons from Cs-137 were evaluated using a standard Cs-137 planar source (JRIA), sealed with plastic ( $1 \mathrm{~mm}$ thick on one side) with a diameter of $37 \mathrm{~mm}$ and radioactivity of $992 \mathrm{~Bq}$. The planar source with a diameter of $37 \mathrm{~mm}$ was as large as the deposits collected in the filter.

The 10 -mm-thick acrylic plate removes the $\beta$-rays from Cs-137 so that only the photons from Cs-137 are measured. The measurement obtained using the above standard source when the 10 -mm-thick acrylic plate was used was $1.0 \times 10^{-3} \mathrm{cps} / \mathrm{Bq}$. In the case of a 2 -mm-thick polyethylene plate, the $\beta$ rays from Cs- 137 can be ignored and only the photons from Cs-137 are measured. The measurement obtained under this condition using a standard source was $1.43 \times 10^{-3} \mathrm{cps} / \mathrm{Bq}$.

Therefore, based on the count rate $\left(C_{a c}\right)$ with a 10 -mm-thick acrylic plate, the contribution of photons for a 2-mm-thick polyethylene plate $\left(C s_{B G}\right)$ can be determined from the following 
equation using a correction coefficient of 1.43 :

$$
C s_{B G}(c p s)=1.43 \times C_{a c}
$$

In the actual measurements, the value which is obtained after deducting $C s_{B G}$ from the count rate for a 2-mm-thick polyethylene plate is used as the count rate based on the $\beta$-rays from Y-90, and the concentration of Y-90 is calculated using the conversion coefficient of Y-90.

Based on the conversion coefficient of Y-90 when a 2-mm-thick polyethylene plate is used in a $100 \mathrm{~mL}$ water sample, the count rate of $\mathrm{Y}-90$ per $\mathrm{Bq} / \mathrm{cm}^{3}$ is $11.8 \mathrm{cps}$, and this corresponds to the case where $100 \mathrm{~Bq}$ of Y-90 exists on the filter (with a diameter of $37 \mathrm{~mm}$ ) at a concentration of $0.11 \mathrm{cps}$ per Bq. On the other hand, as described above, the count rate per Bq of Cs-137 collected in the filter is $1.43 \times 10^{-3} \mathrm{cps}$, which indicates a significant difference between both the values. In addition, as described in (2) below, the filter's efficiency in collecting radioactive $\mathrm{Cs}$ is extremely low when radioactive Cs exists in the ionic state. Therefore, this suggests that the influence of the photons from Cs-134 and Cs-137 is very small.

On the basis of the above discussion, it can be inferred that the contribution of the photons from nuclides such as Cs-134 and Cs-137 to the measurements of Y-90 is approximately 1/100 even if Cs-134 and Cs-137 exist on the filter in the same radioactive concentration as Sr-90.

\section{(2) Efficiency of collecting Cs-137 in the filter}

A solution of $\mathrm{CsCl}$ was added to the aforementioned pure water-based solution used in the experiment of separating $\mathrm{Sr}$ and $\mathrm{Y}$ with a filter, to adjust the concentration of $\mathrm{Cs}^{+}$used as a carrier to $10 \mathrm{ppm}$. The same separation process was carried out after adding the standard Cs-137 solution with a concentration of $1.11 \times 10^{4} \mathrm{~Bq}$ to this solution. The deposits collected in the filter paper were dissolved in hydrochloric acid, and the solution thus prepared along with the undiluted solution before adding $\mathrm{Na}_{2} \mathrm{CO}_{3}$ were put into $20-\mathrm{mL}$ vials and measured with a Ge semiconductor detector to quantitate the Cs-137. It was found that Cs-137 collected in the filter accounted for $0.17 \%$ of the total deposits. It is considered that K-40, a naturally derived substance which may be present in the actual measurement samples, is also eliminated in the course of the deposition and separation processes due to its chemical properties.

On the other hand, it was reported ${ }^{15)}$ as an example that most of the Cs-134 and Cs-137 exist in the RO-concentrated salt water from the $1 \mathrm{~F}$ power station while adsorbing to colloids and suspended solids. In addition, it is considered that the properties of the water samples to be examined vary widely. In many cases, it is established that most of the Cs-134 and Cs-137 are collected in the filtrate and eliminated by the separation process carried out according to this method. However, the collection of these nuclides in the filter must be verified by using actual samples.

\section{Detection Limit of this Method}

The detection limit of concentration of Y-90 and Sr-90 in the measurement of $\beta$-rays from Y-90 was studied using the filter method.

The detection limit is expressed by the following equation ${ }^{16)}$ :

$$
n=(k / 2)\left(k / t+\sqrt{(k / t)^{2}+4 n_{b}\left(1 / t+1 / t_{b}\right)}\right)
$$

where, $n$ is the count rate of the detection limit (cps), $k$ is the confidence level, $t$ is the sample measurement time, $t_{b}$ is the background measurement time, and $n_{b}$ is the background count rate 
(cps).

In this experiment with standard Sr-90 samples, the background of the measurement environment where shielding with lead was applied (under the condition where there was a 10-mmthick acrylic plate and no measurement sample) was $0.45 \mathrm{cps}$. The detection limit of Y-90 was evaluated using this value. With the filter sample and background measurement time of 10 min and $k=3$, the detection limit $(n)$ was $0.13 \mathrm{cps}$. When the conversion coefficients for $100 \mathrm{~mL}$ and $400 \mathrm{~mL}$ water samples with a 2-mm-thick polyethylene plate were used, the detectable radioactive concentration limits of $\mathrm{Sr}-90$ were calculated from radioactive equilibrium as $0.012 \mathrm{~Bq} / \mathrm{cm}^{3}$ and $0.0032 \mathrm{~Bq} / \mathrm{cm}^{3}$, respectively (the radioactive concentration of $\mathrm{Y}-90$ is the same).

However, in the actual sample measurement, a 10-mm-thick acrylic plate was introduced as there was a mixing of radioactive Cs and the background, including the contribution of photons, denoted by $n_{b}$.

As described previously, most of the radioactive $\mathrm{Cs}$ is eliminated in the deposition-filtration process, and the contribution to the background is as small as $1.43 \mathrm{E}-3 \mathrm{cps}$ per Bq. Therefore, it is considered that the background specific to the measurement environment is dominant in the actual sample measurements. Based on the assumption that the background of the measurement environment at the $1 \mathrm{~F}$ power station is approximately twice $(1.0 \mathrm{cps})$ as large as that of this experiment, the detection limit was evaluated using this value as $n_{b}$. If the sample and background are both measured for $10 \mathrm{~min}$ and $k=3$, the detectable count rate limit $n$ is $0.19 \mathrm{cps}$. In this case, when the conversion coefficients for $100 \mathrm{~mL}$ and $400 \mathrm{~mL}$ water samples with 2-mm-thick polyethylene plate are also used, the detectable radioactive concentration limits of Y-90 were calculated as $0.017 \mathrm{~Bq} / \mathrm{cm}^{3}$ and $0.0045 \mathrm{~Bq} / \mathrm{cm}^{3}$, respectively. Therefore, the detection limit depends primarily on the measurement time and background of the measurement environment. As the measurement of the above level of radioactive concentration of Y-90 is achieved, it indicates that it is feasible to measure the same level of radioactive concentration of Sr-90.

\section{Conclusions}

A filter method was developed to facilitate the measurement of a relatively low level of Sr90 concentration in various types of water samples generated at the current $1 \mathrm{~F}$ power station.

1. Sr-90 and Y-90 are concentrated and collected in a filter at high collection efficiency using the carbonate precipitation and iron coprecipitation methods. A 2-mm-thick polyethylene plate ( $\beta$-ray absorber) was used as a filter to enable the selective measurement of high-energy $\beta$-rays from Y-90 with a GM counter tube.

2. Most of the radioactive Cs existing in the water samples in the ionic state was eliminated by the deposition and separation processes that were carried out according to this method. If mixed nuclides such as Cs-134 and Cs-137 existed in the filter, the contribution of the photons from such nuclides was evaluated by inserting a $10-\mathrm{mm}$-thick acrylic plate. However, even if these nuclides had the same concentration as $\mathrm{Sr}-90$, their contribution to the count rates of Y-90 was as small as 1/100.

3. In the filter method, the concentration of Sr-90 was evaluated in a single measurement as long as Sr-90 and Y-90 achieved a state of secular equilibrium. Otherwise, the radioactive concentration of Sr-90 could be evaluated with the equation derived from the sequential decay of Sr-90 and Y-90 by conducting the measurements twice at a certain interval and then determining the radioactive concentrations of Y-90 both times using the conversion 
coefficient from the obtained count rate of the $\beta$-rays from Y-90. The time taken to conduct the separation and collection processes and the measurement is $30 \mathrm{~min}$ or less, hence, it is possible to obtain results within 6 hours even if it is necessary to conduct the measurement twice. It is possible to measure concentrations that are much lower than the tentative effluent standard related to $\mathrm{Sr}-90\left(0.01 \mathrm{~Bq} / \mathrm{cm}^{3}\right)$ currently used at the $1 \mathrm{~F}$ power station in a shorter time than that taken using conventional measurement methods.

4. This is a method for measuring the radioactive concentration of Sr-90 easily and quickly without any advanced processes of chemical separation and professional measurement techniques and is considered to make a useful contribution to effluent management at the $1 \mathrm{~F}$ power station which has a large number of water samples to be examined.

When applying this method to a field site, the following points need to be noted:

1. The most important objective of the filter method is to measure high-energy $\beta$-rays from Y-90 precisely and selectively. If any nuclide other than Y-90 which emits high-energy $\beta$-rays is present (potentially, such as Rh-106 which is a daughter nuclide of Ru-106 or Pr-144 which is a daughter nuclide of Ce-144), the contribution of such a nuclide must be evaluated.

2. If nuclides which interfere with the measurement of $\beta$-rays from Y-90, such as Cs-134 and Cs-137, are present in a high concentration, it is possible to concentrate and collect these nuclides in the filter. Before applying this method, it is necessary to check the amounts of the nuclides that are concentrated and collected in the filter using an actual sample obtained from the $1 \mathrm{~F}$ power station.

3. If a water sample contains seawater at a concentration of $20 \%$ or higher, a large amount of deposit may be attached to the area around the funnel, causing difficulty in handling. The samples with high seawater concentrations need to be studied separately.

\section{References}

1) Tokyo Electric Power Company, "Leakage of Contaminated Water at H4 Tank Area," Handout for the 3rd Working Group on Managing Contaminated Water, Commission on Supervision and Evaluation of the Specified Nuclear Facility, Document No.1, 2013 Aug 21. [in Japanese]. http://www.nsr.go.jp/ data/000051216.pdf, cited 2015.Feb 26.

2) Ministry of Education, Culture, Sports, Science and Technology, Series of Radioactivity Measurement Method 2; Method of Radioactive Strontium Analysis (2003). [in Japanese]

3) Tokyo Electric Power Company, "Recent Leakage of Contaminated Water from Storage Tank and Weir, Causes and Remedies for This Matter," Handout for the 10th Working Group on Managing Contaminated Water, Commission on Supervision and Evaluation of the Specified Nuclear Facility, Document No. 2 , 2014 Jan 24. [in Japanese]. http://www.nsr.go.jp/data/000051256.pdf, cited 2015.Feb 26.

4) N. Vajda, C. Kim, "Determination of radiostrontium isotopes: A review of analytical methodology," Appl. Radiat. Isot., 68, 2306 (2010).

5) "The Law for the Regulations of Nuclear Source Material, Nuclear Fuel Material and Reactors," ed. Study Group on Legislation and Regulations on Nuclear Safety, Taisei Publishing Company, Tokyo, pp. 544 (2009). [in Japanese]

6) Tokyo Electric Power Company, "Provisional Effluent Standards for Contaminated Water," Handout for the 8th Working Group on Managing Contaminated Water, Commission on Supervision and Evaluation of the Specified Nuclear Facility, Additional Material, 2013 Oct 15. [in Japanese]. http://www.nsr.go.jp/ data/000051248.pdf (cited 2015 Feb 26)

7) Handbook of Analytical Chemistry, ed. Japan Soc. For Analytical Chemistry, Maruzen, Tokyo, pp. 132, 139 (1991). [in Japanese]

8) Japan Radioisotope Association. Radiation and Isotopes, pp. 360 (1997). [in Japanese]

9) Tokyo Electric Power Company, "Present Status of the Study in Working Group on Managing Contaminated Water," Handout for the 15th Working Group on Managing Contaminated Water, Commission on Supervision and Evaluation of the Specified Nuclear Facility, Document 3-2, 2013 Oct 30. [in Japanese]. http://www.nsr.go.jp/data/000051009.pdf, cited 2015 Feb 26. 
10) Tokyo Electric Power Company, "Present Status of the Study in Working Group on Managing Contaminated Water," Handout for the 7th Working Group on Managing Contaminated Water, Commission on Supervision and Evaluation of the Specified Nuclear Facility, Document No. 2, 2013 Sep 30. [in Japanese], http://www.nsr.go.jp/data/000051240.pdf, cited 2015 Feb 26

11) Japan Radioisotope Association, Radioisotope Pocketbook 11th edition, Maruzen, Tokyo, ISBN978-489073-211-1C3049. (2011). [in Japanese]

12) H. Hirayama, Y. Namito, A. F. Bielajew, S. J. Wilderman, W. R. Nelson, The EGS5 Code System, SLAC-R-730 (2005) and KEK Report 2005-8 (2005).

13) Tokyo Electric Power Company, "Leakage of Contaminated Water at H4 Tank Area," Handout for the 5th Working Group on Managing Contaminated Water, Commission on Supervision and Evaluation of the Specified Nuclear Facility, Document No. 2, 2013 Aug 30. [in Japanese]. [Internet], http://www.nsr. go.jp/data/000051227.pdf (cited 2015 Feb 26).

14) Hitachi Aloka Medical, Ltd, "GM Survey meter TGS-146B," [Internet], http://www.hitachi-aloka.co.jp/ products/data/radiation-002-TGS-146 (cited 2015, February 26).

15) Ministry of Economy, Trade and Industry, "Main Subjects concerning the Advanced Liquid Processing System and Purposes of Laboratory and Verification Experiments," Handout for the 1st Task Force on the Advanced Liquid Processing System, Document No 3, 2013 Nov 29. [in Japanese]. http://www.meti. go.jp/earthquake/nuclear/pdf/131129/131129_03e.pdf ( 2015.2.26 final confirmation).

16) K. Minami, "On Two Formulas Regarding Count Rates for Detection Limit." Jpn. J. Health Phys. (Hoken Butsuri), 17,79 (1982). [in Japanese] 